\title{
Electrodeposition of Nanocrystalline Chromium-Carbon Alloys from Electrolyte Based on Trivalent Chromium Sulfate Using Pulsed Current
}

\author{
F. I. Danilov', V. S. Protsenko'1, V. O. Gordiienko'1, A. S. Baskevich', and V. V. Artemchuk ${ }^{2}$ \\ ${ }^{1}$ Ukrainian State University of Chemical Technology, Gagarin Av. 8, 49005 Dnepropetrovsk, Ukraine \\ e-mail:fdanilov@optima.com.ua \\ ${ }^{2}$ Dnipropetrovsk National University of Railway Transport named after Academician V. Lazaryan, \\ Lazaryana St. 2, 49010 Dnepropetrovsk, Ukraine
}

Received September 13, 2011

\begin{abstract}
The effect of the parameters of pulsed electrolysis on the current efficiency, nanocrystal size, composition, hardness, friction coefficient, and wear resistance of nanocrystalline $\mathrm{Cr}-\mathrm{C}$ coatings obtained from electrolyte based on $\mathrm{Cr}$ (III) sulfate containing carbamide and formic acid is studied. It is shown that coatings contain $\sim 9$ wt $\%$ of carbon; the current density and pulse ratio produce practically no effect on their composition. It is found that a maximum appears on the dependence of current efficiency on pulse ratio in the case of the pulse ratio of $\sim 1.05-1.1$. Thereby, current efficiency greatly exceeds the value implemented in the steady-state current mode. It is shown that, if the microhardness of $\mathrm{Cr}-\mathrm{C}$ deposits obtained at constant current is close to $850-900 \mathrm{HV}$, the microhardness may increase to $\sim 1200-300 \mathrm{HV}$ when pulsed electrolysis is used in certain modes. It is found that application of pulsed electrolysis allows a significant decrease in the friction coefficient of chromium-carbon coating (steel counterbody) both under the dry friction conditions and in the case of boundary lubrication and also results in an increase in the deposit wear resistance.
\end{abstract}

DOI: $10.1134 / \mathrm{S} 2070205112030057$

\section{INTRODUCTION}

Obtaining thick chromium coatings from electrolytes based on trivalent chromium compounds is one of the key problems in modern electroplating [1-11]. In recent decades, significant progress has been achieved in this direction which is related both to development of new effective electroplating technologies and to a deeper understanding of the kinetics and mechanism of the processes occurring under chromium plating. It has been shown that problems in synthesis of thick $\mathrm{Cr}$ deposits from $\mathrm{Cr}$ (III) solutions are primarily due to the processes of hydrolysis of the electrolyte components in the near-electrode layer and further inclusion of low-soluble hydroxy compounds of chromium into the deposit $[12,13]$. Therefore, a correct choice of the nature and concentration of organic additives (ligands, buffers, water-soluble polymers) allowing providing the optimum state of the near-electrode layer in the process of chromium plating and suppressing hydroxide formation is of fundamental importance [14-18].

A promising method for obtaining thick $\mathrm{Cr}$ deposits with satisfactory mechanical performance characteristics can be electrodeposition using pulsed current [19-21]. In [21], the possibility of thick-layer chromium plating was shown in $\mathrm{Cr}$ (III) formate-sulfate electrolyte using the pulsed electrolysis mode. At the same time, a drawback of the electrolyte used consists in low values of current efficiency (not more than 10$15 \%$ ) and deposition rate (about $0.1-0.2 \mu \mathrm{m} / \mathrm{min}$ ).

Chromium-plating electrolytes based on $\mathrm{Cr}$ (III) containing carbamide and formic acid as organic additives have been proposed in recent years. Nanocrystalline chromium-carbon alloys were deposited from these electrolytes at a rather high current efficiency, reaching $30 \%$ or more (at a deposition rate of $1-1.5 \mu \mathrm{m} / \mathrm{min}$ or more) $[3,4,17,18,22-24]$.

The aim of this work consisted in studies of the effect of pulsed electrolysis parameters on the current efficiency of the process of electrodeposition of $\mathrm{Cr}-\mathrm{C}$ alloy of carbamide-formiate electrolyte based on trivalent chromium salts, as well as on the most important performance characteristics of $\mathrm{Cr}$ deposits: their microhardness and tribotechnical properties.

\section{EXPERIMENTAL}

The electrolyte composition used $\left(\mathrm{mol} / \mathrm{dm}^{3}\right)$ for chromium deposition was: $0.5 \mathrm{Cr}_{2}\left(\mathrm{SO}_{4}\right)_{3} \cdot 6 \mathrm{H}_{2} \mathrm{O}$ (i.e. $\left.1 \mathrm{M} \mathrm{Cr} \mathrm{Cr}^{+3}\right), \quad 0.5 \mathrm{HCOOH}, \quad 0.5 \quad \mathrm{CO}\left(\mathrm{NH}_{2}\right)_{2}$, $0.15 \mathrm{Al}_{2}\left(\mathrm{SO}_{4}\right)_{3} \cdot 18 \mathrm{H}_{2} \mathrm{O}, 0.3 \mathrm{Na}_{2} \mathrm{SO}_{4}, 0.5 \mathrm{H}_{3} \mathrm{BO}_{3}$, and $0.1 \mathrm{~g} / \mathrm{dm}^{3}$ sodium laurilsulfate [22-24].

Electrodeposition was carried out in a thermostated glass cell. A pulsed PI-50-1.1 potentiostat with 
a PR-8 programmer was used to set the pulsed current. Deposition was carried out on the surface of a copper plate $\left(S=1 \mathrm{~cm}^{2}\right)$ that was degreased prior to electrolysis using an aqueous $\mathrm{MgO}$ paste activated in a hydrochloric acid solution and thoroughly rinsed with distilled water.

The pulse ratio was calculated according to the following formula:

$$
Q=\frac{\tau_{i}+\tau_{p}}{\tau_{i}}
$$

where $\tau_{i}$ is the pulse duration (s); $\tau_{p}$ is the pause duration (s).

Titanium dioxide-manganese (TMD) electrodes were used as anodes [25]. The reaction of oxidation of the $\mathrm{Cr}$ (III) ions to $\mathrm{Cr}(\mathrm{VI})$ on TMD occurs at a low rate, which allows carrying out electrolysis without separation of the cathodic and anodic compartments.

The chromium content in the coating was determined using the method of X-ray photoelectron spectroscopy (XPS) [24] and spectrophotometric analysis. In the latter case, the deposited $\mathrm{Cr}-\mathrm{C}$ coating was dissolved in hydrochloric acid and then optical density of the solution was measured after formation of an intensively colored $\mathrm{Cr}$ (III) complex with EDTA was measured at $\lambda=540 \mathrm{~nm}$ according to the standard technique [26] and the chromium content in the deposit (Cr\%) was calculated. The carbon content in the deposit was found on the basis of the difference of $\mathrm{C} \%=100 \%-\mathrm{Cr} \%$. The results of determining the coating composition using the XPS technique and spectrophotometric technique coincide satisfactorily.

Current efficiency (CE) of chromium was calculated on the basis of the data of gravimetric measurements per three-electron overall reaction of $\mathrm{Cr}(\mathrm{III})+3 e^{-} \rightarrow \mathrm{Cr}(0)$. The overall amount of electricity that passed through the electrolytic cell was determined using a copper coulometer. Let us note that CE calculations were carried out taking into account the experimentally determined chromium content in the coating ${ }^{1}$.

The structure of the formed chromium coatings was studied using the method of small-angle X-ray scattering (a DRON-3 X-ray diffractometer coupled with a KRM-1 low-angle camera in monochromatic $\mathrm{Cu}-\mathrm{K}_{\alpha}$ radiation) [22].

Microhardness of chromium coatings was measured using a PMT3 microhardness meter with a

\footnotetext{
${ }^{1}$ In our previous paper [21], the correction for the chromium content in the coating was not introduced and it was assumed in the calculations of the current efficiency that the whole electrode weight gain was due to deposition of metallic chromium. This was due to the fact that carbon content in chromium deposits studied in [21] was at least $1 \%$ and could be neglected.
}

charge of $100 \mathrm{~g}$ at the deposit thickness of at least $20 \mu \mathrm{m}$. At least three deposits were obtained in determination of microhardness for every set of specific electrodeposition conditions, measurements were carried out in at least five points of each sample, and then the arithmetic mean value was calculated.

The tribotechnical characteristics of the deposits were studied at an SMT-2 friction machine according to the "disk-shoe" scheme. A "shoe" sample cut out of a steel cylindrical ring with outer and inner diameters of 68 and $50 \mathrm{~mm}$, accordingly, and width of $10 \mathrm{~mm}$ was used in the tests. A chromium coating with thickness of $\sim 20 \mu \mathrm{m}$ was applied on the inner "shoe" surface. The counterbody was a disk of steel 45 tempered to the depth of $2.5-3 \mathrm{~mm}$ at a hardness of HRC 4560 . The tests were carried out at the sliding speed of $0.79 \mathrm{~m} / \mathrm{s}$ (the counterbody rotation frequency was $300 \mathrm{rpm})$. The overall friction path length of each test sample was $3140 \mathrm{~m}$. The friction was carried out without lubrication and under the boundary lubrication conditions using M14 (Diesel). The average wear was determined on the basis of gravimetric measurements.

\section{EXPERIMENTAL RESULTS AND DISCUSSION}

\section{Chemical Composition of Deposits, Current Efficiency of Chromium Deposition Reaction and Appearance of Coatings}

As shown earlier [22], deposits obtained from electrolyte based on $\mathrm{Cr}$ (III) with additives of carbamide and formic acid contain a rather large amount of carbon in the form of carbide; i.e., chromium-carbon alloy is actually deposited. The studied coatings contain $\sim 91$ wt $\%$ of $\mathrm{Cr}$ and $\sim 9$ wt $\%$ of C, which approximately corresponds to the stoichiometry of the $\mathrm{Cr}_{7} \mathrm{C}_{3}$ carbide. As follows from the data obtained, the pulse ratio in the range of its variation from 1 to 3 produces practically no effect on the carbon content in the alloy. Thus, the transition from steady-state electrolysis to the pulsed mode does not affect the carbon content at the applied values of the deposition current density $\left(30,35\right.$, and $\left.40 \mathrm{~A} / \mathrm{dm}^{2}\right)$ within the experimental error.

As seen from the obtained data (Fig. 1), the $C E$ value depends in a rather complex way on the pulse ratio. The character of this dependence is largely determined by the current pulse duration and also by the pulse current density.

An increase in the pulse ratio results in a decrease in the $C E$ value at a relatively low current pulse duration $\left(\tau_{i}=0.5 \mathrm{~s}\right)$ as compared to the steady-state mode.

The character of the $C E, Q$-dependence changes fundamentally, if the pulse duration is increased. As seen in Fig. 1 (curves 2 and 3), a maximum corre- 


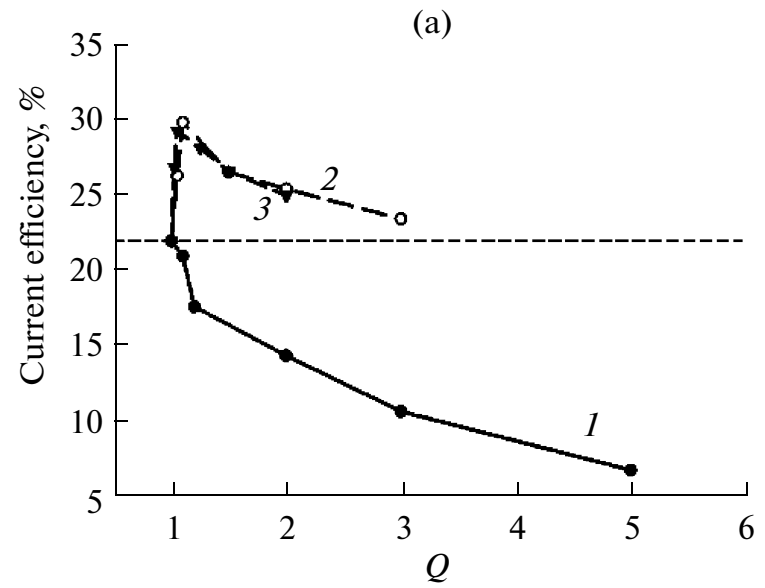

(b)
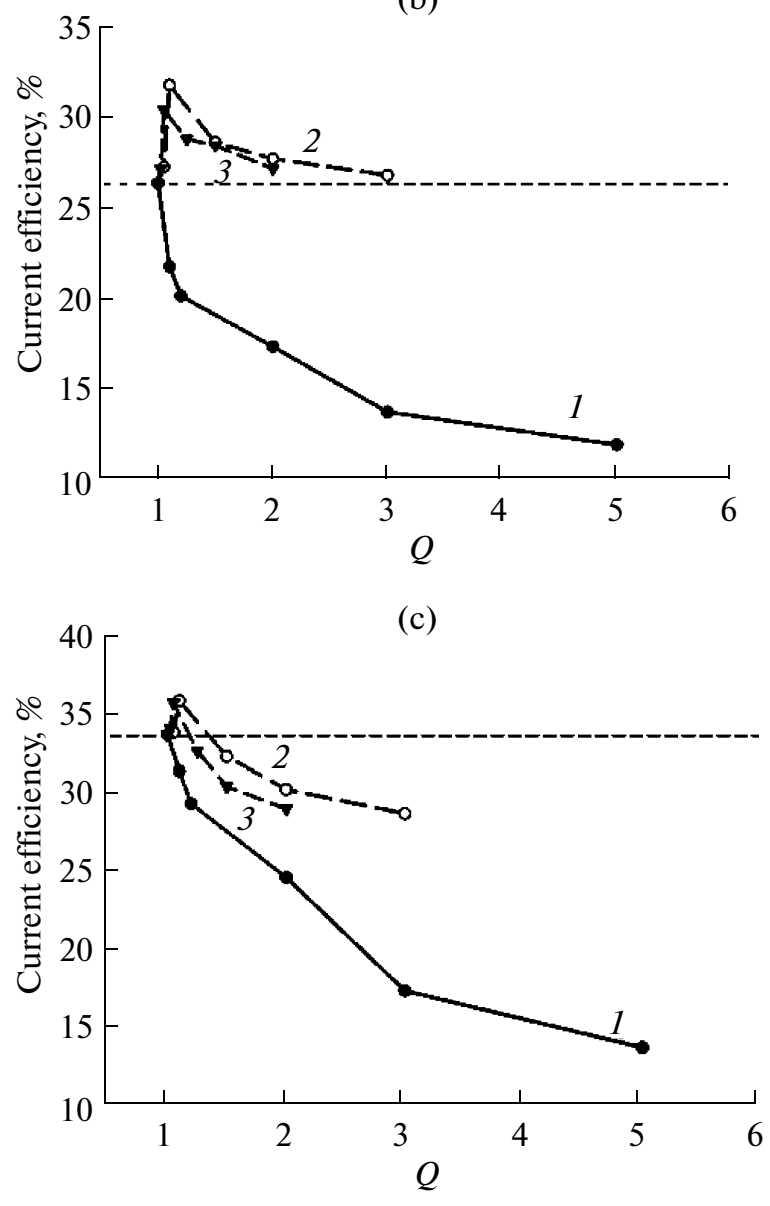

Fig. 1. Dependence of current efficiency on the pulse ratio for different duration of current pulses (s): (1) 0.5 , (2) 1 , (3) 2. Pulsed current density $\left(\mathrm{A} / \mathrm{dm}^{2}\right)$ : (a) 30, (b) 35, (c) 40.

sponding to $Q \approx 1.05-1.1$ appears in the discussed dependence at $\tau_{i}=1$ and $\tau_{i}=2 \mathrm{~s}$. Herewith, current efficiency obtained at $\tau_{i}=1 \mathrm{~s}$ is generally higher than at $\tau_{i}=2 \mathrm{~s}$. One should also note that current efficiency at the $Q$ values corresponding to the maximum in the analyzed dependence exceeds noticeably the value obtained in the steady-state current mode.
It is of interest that a similar extremal character of the $C E, Q$-dependence was observed earlier [21] under chromium electrodeposition from electrolyte based on $\mathrm{Cr}(\mathrm{III})$. Its composition differs significantly from that used in the present work.

The obtained $C E$ and $Q$ dependences can be interpreted on the basis of the modern concepts of the mechanism of chromium electrodeposition from electrolytes based on trivalent chromium compounds [13, 27-29], according to which this process occurs under the conditions of formation of low-soluble hydroxy $\mathrm{Cr}$ (III) compounds ("cathodic film") in the nearcathode electrolyte layer. Formation of this film is due to an increase in $\mathrm{pH}_{S}$ in the near-electrode layer due to occurrence of the corresponding hydrogen electroevolution reaction. The $\mathrm{pH}_{S}$ value obviously decreases approaching the bulk value under pulsed electrolysis in the pause period. As a consequence, the amount of low-soluble $\mathrm{Cr}$ (III) compounds in the near-electrode layer decreases, which must result in a decrease in the amount of adsorbed hydroxide compounds of trivalent chromium blocking the electrochemical chromium deposition process. Ultimately, the current efficiency may increase at certain $Q$ and $\tau_{i}$ values (the maximum in the experimental $C E, Q$-curve).

One should note that discharge of the complex $\mathrm{Cr}(\mathrm{III})$ ions to the metallic state occurs stagewise with formation of intermediate $\mathrm{Cr}$ (II) compounds [11, 13, $27,29]$. Herewith, the limiting process stage is electroreduction of bivalent chromium ions. Additional convective-diffusive removal of $\mathrm{Cr}$ (II) ions into the bulk of electrolyte occurs under pulsed electrolysis in the period of the current pause. The concentration of these ions near the cathode surface decreases, and the rate of chromium electrodeposition decreases regularly (the decreasing region in the $C E, Q$-dependence). This effect becomes especially pronounced at low pulse duration (see curves 1 in Figs. 1a, 1b, 1c).

The appearance of deposits obtained under pulsed current does not differ from the appearance of coatings deposited under the steady-state mode, all other conditions being similar. The formed coatings are smooth and bright.

\section{Structure of Chromium-Carbon Deposits}

It was shown earlier using the method of smallangle $X$-ray scattering [22] that the chromium-carbon alloy coatings have a nanocrystalline structure. It is found in this study that an increase in the pulse ratio leads to a certain decrease in the radii of inhomogeneities (regions of ordered atom arrangement) $R_{0}$ (Table 1). These data are similar to those obtained in [21]. 


\section{Deposit Microhardness}

As follows from the data presented in Fig. 2, the dependence of the coating microhardness on the relative pulse duration has an extremal character. Herewith, the microhardness value somewhat grows in the curve maximum at an increase in the pulse ratio. One can also note that the maximum in the microhardness $Q$-dependence shifts toward a lower pulse ratio at an increase in the pulse duration (thus, the highest microhardness is observed at $Q=3,2$, and 1.5 , accordingly, for $\tau_{i}=0.5,1$, and $2 \mathrm{~s}$ ).

It is known [30] that microhardness of chromium deposits depends significantly on the size of crystallites, residual stress, and inclusions into the structure of various metallic and nonmetallic phases. When pulsed current is used, the effect of partial chromium passivation is observed in the pause period (as wellknown, metallic chromium rather tends to self-passivation in aqueous solutions [31]), which assists formation of a large amount of new nanosize nuclei during the following current pulse. This obviously explains the decrease in the size of the formed nanocrystals observed at an increase in $Q$ resulting in an increase in the coating microhardness. The further passivation of the current pause duration and the obviously associated increasing surface passivation can cause deterioration of the bond strength between the deposited chromium layers and the deposit microhardness starts decreasing (see Fig. 2).

\section{Tribotechnical Characteristics of Chromium-Carbon Alloy Coatings}

For tribotechnical studies, chromium-carbon deposits were deposited using pulsed current at the pulse and pause durations of 1 s (i.e., at $Q=2$ ), as rather hard deposits are formed in these modes according to the above data. The test results are presented in Tables 2 and 3, whence it follows that the friction coefficients and average wear of coatings obtained under pulsed current are noticeably lower than the corresponding values for coatings deposited under the steady-state current mode both under dry friction conditions and in the presence of boundary lubrication.

We believe that improvement of the tribotechnical characteristics of chromium-carbon coatings under the pulsed electrodeposition mode is due to the above size reduction of nanocrystals. This assumption agrees well with the modern concepts as to the fact that the friction coefficient and wear resistance (alongside with hardness) belong to the properties of nanocrystalline galvanic coatings strongly depending on the nanocrystal size [32].
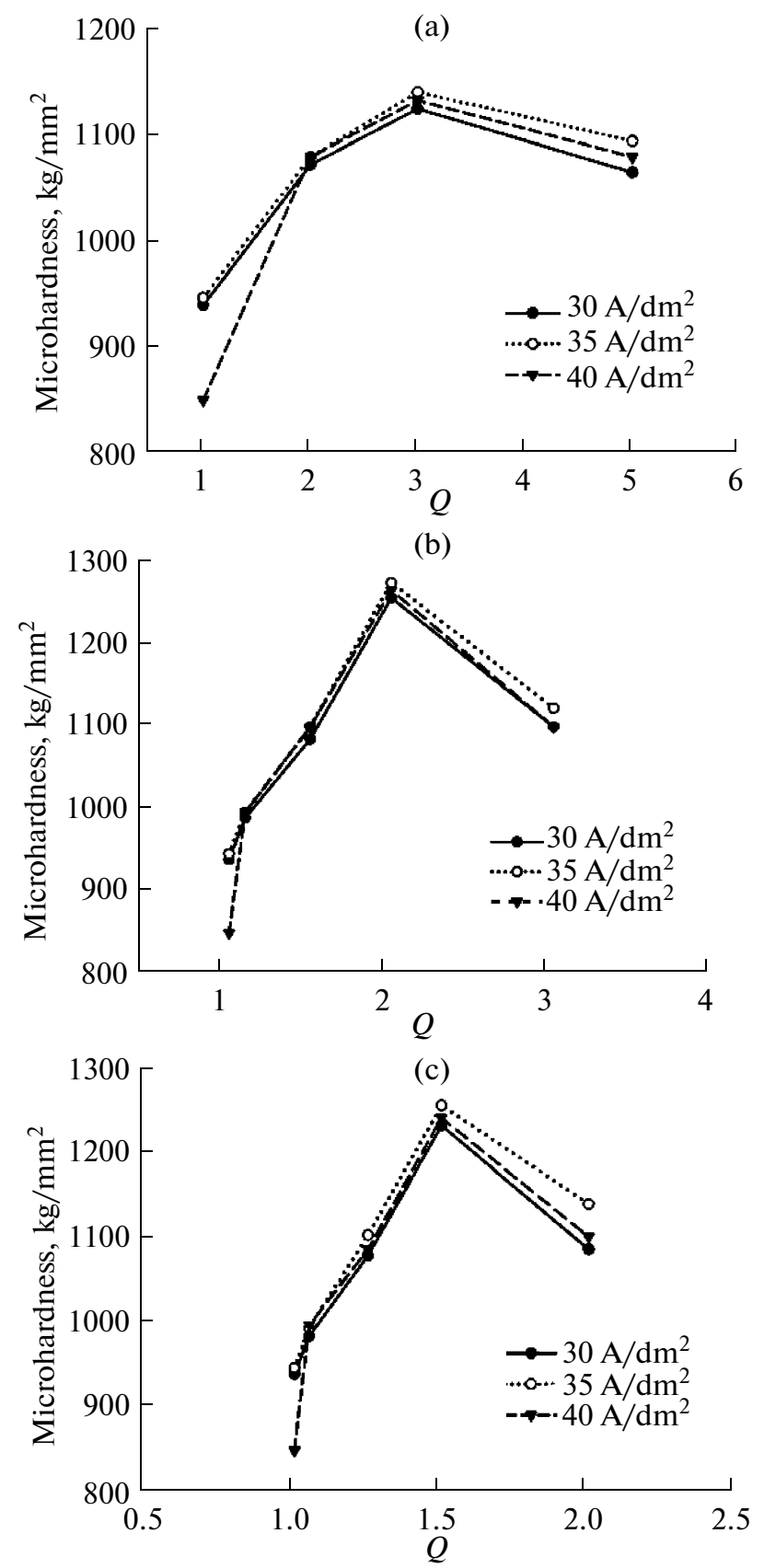

Fig. 2. Dependence of coating microhardness on the pulse ratio for different duration of current pulses (s): (a) 0.5 , (b) 1 , (c) 2 .

Table 1. Effect of the pulsed current on the heterogeneity radius (regions of ordered atom arrangement) in the chromium-carbon deposit structure

\begin{tabular}{l|c}
\hline \multicolumn{1}{c|}{ Deposition mode } & $R_{0}, \mathrm{~nm}$ \\
\hline Steady-state electrolysis $(Q=1)$ & 3.5 \\
Pulsed electrolysis & 3.2 \\
$\tau_{i}=1 \mathrm{~s}, \tau_{p}=0.5 \mathrm{~s}(Q=1.5)$ & 3.0 \\
Pulsed electrolysis \\
$\tau_{i}=1 \mathrm{~s}, \tau_{p}=1 \mathrm{~s}(Q=2)$ \\
\hline \multicolumn{2}{l}{ Note: Pulsed current density, $35 \mathrm{~A} / \mathrm{dm}^{2}$. Temperature, $35^{\circ} \mathrm{C}$}
\end{tabular}


Table 2. Dependence of the friction coefficient of chromium-carbon coatings on the electrodeposition conditions (at the specific load of $1 \mathrm{MPa}$ )

\begin{tabular}{c|c|c|c|c}
\hline \multirow{2}{*}{$\begin{array}{c}\text { Current density, } \\
\text { A/dm }\end{array}$} & \multicolumn{3}{|c}{ Friction coefficient } \\
\cline { 2 - 5 } & \multicolumn{2}{|c|}{ Dry friction } & \multicolumn{2}{c}{ Boundary lubrication } \\
\cline { 2 - 5 } & $\begin{array}{c}\text { Steady-state deposition } \\
\text { mode }(Q=1)\end{array}$ & $\begin{array}{c}\text { Pulsed deposition mode } \\
(Q=2)\end{array}$ & $\begin{array}{c}\text { Steady-state deposition } \\
\text { mode }(Q=1)\end{array}$ & $\begin{array}{c}\text { Pulsed deposition mode } \\
(Q=2)\end{array}$ \\
\hline 30 & 0.14 & 0.12 & 0.10 & 0.09 \\
45 & 0.14 & 0.11 & 0.09 & 0.08 \\
0.14 & 0.13 & 0.10 & 0.09 \\
\hline
\end{tabular}

Table 3. Dependence of average wear of chromium-carbon coatings on the conditions of electrodeposition (electrodeposition current density, $35 \mathrm{~A} / \mathrm{dm}^{2}$ )

\begin{tabular}{l|l|c|c|c|c}
\hline \multirow{2}{*}{\begin{tabular}{c}
\multirow{1}{*}{$\begin{array}{c}\text { Friction } \\
\text { conditions }\end{array}$} \\
\cline { 3 - 5 }
\end{tabular}} & $\begin{array}{c}\text { Pulse } \\
\text { ratio }\end{array}$ & \multicolumn{3}{|c}{ Average wear per unit friction path, $\mathrm{g} / \mathrm{km}$} \\
\cline { 3 - 6 } & & 1 & 2 & 3 & 4 \\
\hline Dry friction & $Q=1$ (steady-state mode) & 0.00270 & 0.00495 & 0.00662 & 0.00762 \\
Boundary & $Q=2$ (pulsed mode) & 0.00230 & 0.00445 & 0.00615 & 0.00708 \\
lubrication & $Q=1$ (steady-state mode) & 0.00160 & 0.00290 & 0.00435 & 0.00592 \\
\hline
\end{tabular}

\section{CONCLUSIONS}

It is found that transition from steady-state electrolysis to the pulsed mode does not affect the carbon content at the applied values of the deposition current density $\left(30,35\right.$, and $\left.40 \mathrm{~A} / \mathrm{dm}^{2}\right)$ within the experimental error. A decrease in the nanocrystal size is observed at an increase in the relative pulse duration.

It is shown that the current efficiency of the chromium electrodeposition process at the pulse ratio of $Q \approx 1.05-1.1$ significantly exceeds the value characteristic for steady-state electrolysis. The microhardness of the $\mathrm{Cr}-\mathrm{C}$ deposits may increase to $~ 1200-$ $1300 \mathrm{HV}$ when pulsed electrolysis under certain modes is used. It is found that application of pulsed electrolysis allows significantly decreasing the friction coefficient of the chromium-carbon coatings and increasing the coatings wear resistance.

One should note that the possibility of obtaining electrodeposited nanocrystalline $\mathrm{Cr}-\mathrm{C}$ coatings with extremely high antifriction characteristics and enhanced hardness after their additional thermal treatment was shown earlier in [33]. In our paper, the possibility of significant improvement of tribotechnical characteristics and microhardness of chromium-carbon electrodeposits was established for the first time using pulsed electrolysis without application of a power-consuming procedure of their thermal treatment.

\section{REFERENCES}

1. Edigaryan, A.A. and Polukarov, Yu.M., Prot. Met., 1998, vol. 34, no. 2, p. 117.

2. Edigaryan, A.A. and Polukarov, Yu.M., Prot. Met., 1999, vol. 35 , no. 1 , p. 1 .

3. Kudryavtsev, V.N., Vinokurov, E.G., and Kuznetsov, V.V., Gal'vanotekh. Obrab. Poverkhn., 1998, vol. 6, no. 1, p. 24.

4. Kuznetsov, V.V., Vinokurov, E.G., and Kudryavtsev, V.N., Russ. J. Electrochem., 2001, vol. 37, p. 699.

5. Safonova, O.V., Vykhodtseva, L.N., Polyakov, N.A., et al., Electrochim. Acta, 2010, vol. 56, p. 145.

6. Edigaryan, A.A., Safonov, V.A., Lubnin, E.N., et al., Electrochim. Acta, 2002, vol. 47, p. 2775.

7. Li, B.S. and Lin, A., Key Eng. Mater., 2008, vol. 373374, p. 200.

8. Hall, T.D., Taylor, E.J., and Inman, M., Plat. Surf. Finish, vol. 97, no. 9, p. 42.

9. Ching An Huang, Yu Wei Liu, Chun-Chen Yang, Surf. Coat. Technol., 2011, vol. 205, p. 3461.

10. Kwon, S.C., Kim, M., Park, S.U., et al., Surf. Coat. Technol., 2004, vol. 183, p. 151.

11. Phuong, N.V., Kwon, S.-C., Lee, J.-Y., et al., Microchem. J., 2011, vol. 99, p. 7.

12. Drela, I., Szynkarczuk, J., and Kubicki, J., J. Appl. Electrochem., 1989, vol. 19, p. 933.

13. Protsenko, V. and Danilov, F., Electrochim. Acta, 2009, vol. 54, p. 5666. 
14. Vinokurov E.G, Prot. Met. Phys. Chem. Surf., 2010, vol. 46, no. 5, p. 615.

15. Lee, J.-Y., Kim, M., and Kwon, S.-C., Trans. Nonferrous Met. Soc. China, 2009, vol. 19, p. 819.

16. Danilov, F.I., Protsenko, V.S., Butyrina, T.E., et al., Prot. Met., 2006, vol. 42, p. 560.

17. Survilene, S., Nivinskiene, O., Cesuniene, A., and Selskis, A., J. Appl. Electrochem., 2006, vol. 36, p. 649.

18. Surviliene, S., Jasulaitiene, V., Nivinskiene, O., and Cesuniene, A., Appl. Surf. Sci., 2007, vol. 253, p. 6738.

19. Baral, A. and Engelken, R., J. Electrochem. Soc., 2005, vol. 152, p. C504.

20. Saravanan, G. and Mohan, S., J. Appl. Electrochem., 2009, vol. 39, p. 1393.

21. Danilov, F.I., Protsenko, V.S., Butyrina, T.E., et al., Prot. Met. Phys. Chem. Surf., 2011, vol. 47, no. 5, p. 598.

22. Danilov, F.I., Protsenko, V.S., Gordiienko, V.O., et al., Appl. Surf. Sci., 2011, vol. 257, p. 8048.

23. Hordienko, V.O., Protsenko, V.S., Kwon, S.C., et al., Mater. Sci., 2011, vol. 46, p. 647.
24. Protsenko, V.S., Gordiienko, V.O., Danilov, F.I. and Kwon, S.C., Met. Finish., 2011, vol. 109, no. 4-5, p. 33.

25. Danilov, F.I. and Velichenko, A.B., Electrochim. Acta, 1993, vol. 38, p. 437.

26. Lavrukhina, A.K. and Yukina, L.V., Analiticheskaya khimiya khroma (Analytical Chemistry of Chromium), Moscow: Nauka, 1979.

27. Danilov, F.I. and Protsenko, V.S., Prot. Met., 2001, vol. 37, p. 223.

28. Korshunov, V.N., Safonov, V.A., and Vykhodtseva, L.N., Russ. J. Electrochem., 2008, vol. 44, p. 255.

29. Danilov, F.I., Protsenko, V.S., and Butyrina, T.E., Russ. J. Electrochem., 2001, vol. 37, p. 704.

30. Choi, Y., Kim, M., and Kwon, S.C., Surf. Coat. Technol., 2003, vol. 169-170, p. 81.

31. Knyazheva, V.M. and Kolotyrkin, Ya.M., Dokl. Akad. Nauk SSSR, 1957, vol. 114, no. 6, p. 1265.

32. Erb, U., Key Eng. Mater., 2010, vol. 444, p. 163.

33. Zeng, Z., Wang, L., Liang, A., et al., Mater. Lett., 2007, vol. 61, p. 4107. 